\title{
Restoring scratched cine-film via reducing light scattering
}

\author{
Qingmeng $\mathrm{X} \mathrm{u}^{1,2} \mathbb{B}$, Feifan $\mathrm{Xu}^{1,2}$ and Daodao $\mathrm{Hu}^{3^{*}}$
}

\begin{abstract}
Scratches on cine-film significantly affect the quality of projected film images forming blackness or brightness. Only blackness can be restored by restoration dispersion. However, why the scratches can or can not be restored is unknown. Herein, unscratched and scratched films were selected, treated with restoration dispersion and investigated from composition and microstructure and its interaction with light. Both superficial and penetrating scratches make film rough and the applying of restoration dispersion decreases the roughness. The darkness in the projected film image resulted by superficial scratch can be restored by restoration dispersion through reducing light scattering, while the brightness induced by penetrating scratch can not be restored by restoration dispersion due to the removal of emulsion layer. This investigation is beneficial for developing new restoration dispersion to improve the quality of projected film images.
\end{abstract}

Keywords: Scratch, Cine-film, Light scattering, Restoration

\section{Introduction}

Cine-film holds an unique and important position in cultural heritage conservation as they can vividly capture instantaneous moments in history, such as the appearance of people with diverse cultural origins and scenes with distinct atmospheres [1]. Take typical black-andwhite cine-film as an example. It consists of protective layer, emulsion layer, film base, and antihalation layer [2-4] (Fig. 1a). The film base is the thickest layer constituting $90 \%$ of the thickness, which is usually made of polyester or cellulose esters and acts as substrate of the film. It is sandwiched between the bottom layer (the antihalation backing, where a gelatin coating is applied to absorb light and minimize secondary exposure [2] and the emulsion layer (the fundamental layer of a film). In this layer, metallic silver developed from light-sensitive silver halide crystals [5] are dispersed in gelatin followed by a top

\footnotetext{
*Correspondence: daodaohu@snnu.edu.cn

${ }^{3}$ Engineering Research Center of Historical and Cultural Heritage

Protection, Ministry of Education, School of Materials Science and Engineering, Shaanxi Normal University, Xi'an, China

Full list of author information is available at the end of the article
}

layer, which is the protective layer consisting of a transparent layer of hardened gelatin protecting the emulsion from damage. In projection, light goes through film with a spatial variation of the fraction of silver, consequently, a film image is projected.

Scratches in polymer are common phenomenon [6]. The scratch process can be defined as a mechanical deformation process where a force or displacement is exerted on another material substrate and moves across its surface [7, 8]. Extensive research efforts have been dedicated to fundamentally understand the scratches of polymers [9-11]. The scratch behaviour of polymers is a complex function of the materials bulk response, normal load and indentor geometry [12-15]. The polymer prevents the mechanical deformation from creating rough micro-scratches [16]. Various scratch features, e.g., mar, fish-scale, parabolic crack, and material removal, were observed from a wide variety of polymeric materials [6]. As mentioned above, the main components of a layered film are polyester and gelatin. The scratch behavior of a multilayered material depends on the rheology of the materials which constitute the different layers [17]. However, the Young's moduli of each layer is closely related

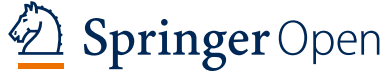

The Author(s) 2021, corrected publication 2021 Open Access This article is licensed under a Creative Commons Attribution 40 International License, which permits use, sharing, adaptation, distribution and reproduction in any medium or format, as long as you give appropriate credit to the original author(s) and the source, provide a link to the Creative Commons licence, and indicate if changes were made. The images or other third party material in this article are included in the article's Creative Commons licence, unless indicated otherwise in a credit line to the material. If material is not included in the article's Creative Commons licence and your intended use is not permitted by statutory regulation or exceeds the permitted use, you will need to obtain permission directly from the copyright holder. To view a copy of this licence, visit http://creativecommons.org/licenses/by/4.0/. The Creative Commons Public Domain Dedication waiver (http:/creativecommons.org/publicdomain/zero/1.0/) applies to the data made available in this article, unless otherwise stated in a credit line to the data. 


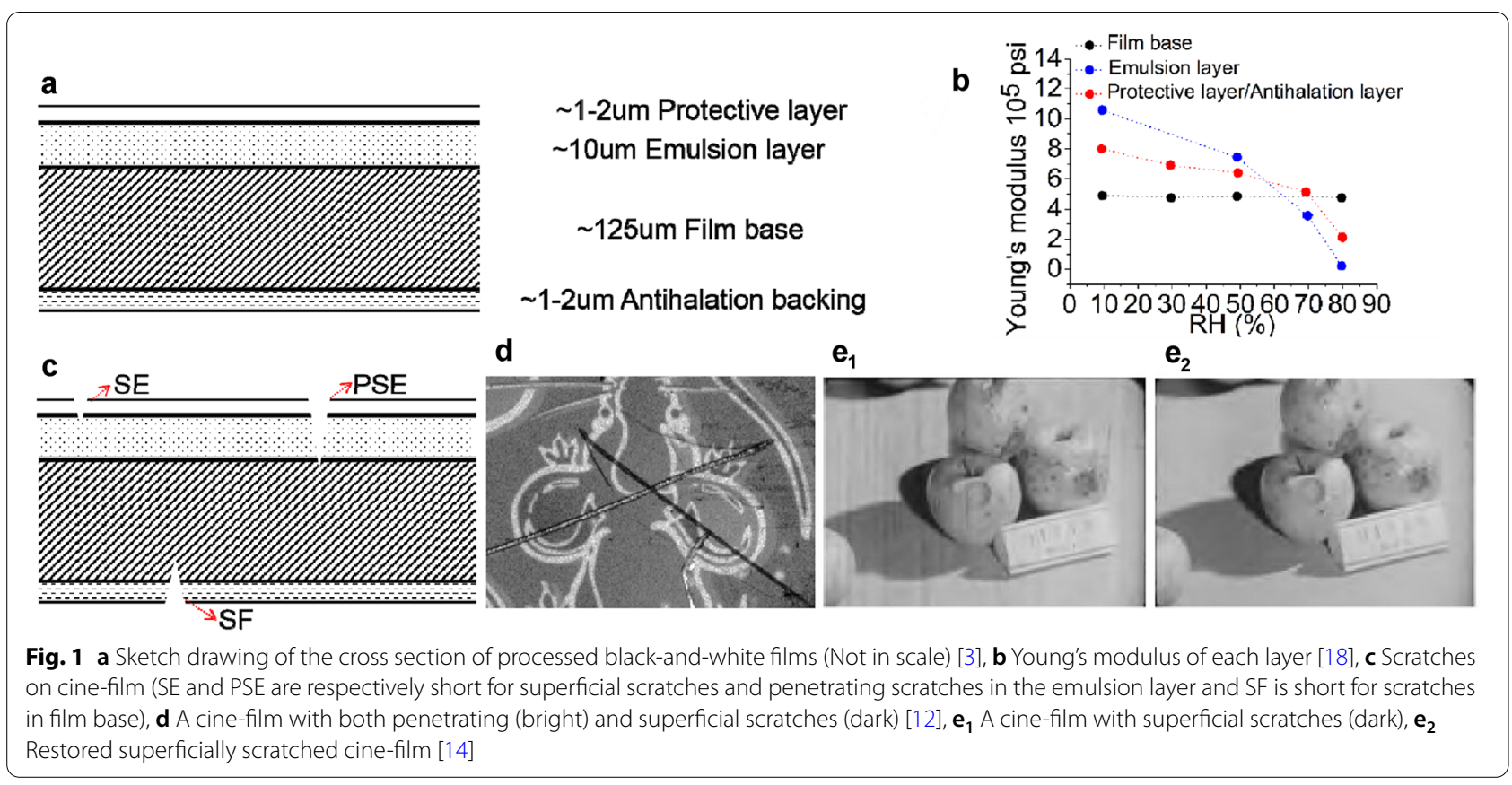

to relative humidity (Fig. 1b) [18]. Scratches can either be superficial or penetrating related to the magnitude of the applied forces [3]. (Fig. 1c). The existing scratches in film can be spots or lines. Polyester films have a greater tendency to generate static electricity and this makes them more susceptible to picking up dust from the atmosphere. The abrasion between dust and film is more susceptible to generating spotted scratches. Throughout the whole manufacturing and projecting process of film, inevitable tribological contacts among films, rollers, and sprockets may generate linear scratches.

The visibility of scratch can critically impact the aesthetics of polymeric surfaces [18]. A large body of research has been developed to quantify its perception [12, 19]. The critical optical parameters that affect the visibility of scratch are the size, roughness of the scratch, the color and gloss of the surroundings [20-22]. While, for the specific material, roughness of the scratch is the significant factor. Computational approaches were studied to predict the link between roughness and the visibility of scratch [23-25]. Roughness affect the scratch's visibility by changing the interaction of light and surface. Light interacts with very smooth surface via absorption, transmittion and reflection contributed only by specular reflection $[19,26]$. However, if the mirror-like surface is abraded, small scratches are introduced on the surface. Thus, light falling upon the surface is scattered, decreasing glossiness [27] and creating the image of scratch on the surface. In other words, the roughness of surface induced by various scratch features alters light reflection characteristics due to light scattering [28], which becomes the source for scratch-induced visibility. In our study, this is confirmed by the alteration of the projected film images (Fig. 1d). Superficial scratches in the film base or emulsion layer are black on the projected film images and penetrating scratch is bright. In order to reduce the effects of scratches on film images, $\mathrm{Li}$ and $\mathrm{Ma}$ [29] developed a restoration dispersion (detailed in section of material). In their study, it was only applied on superficial scratches and the image reappeared (Fig. 1e1, e2) [30]. However, how the restoration dispersion works on the scratches remains unexplored.

In this study, black and white cine-film with superficial and penetrating scratches were selected and applied with restoration dispersion. The effects of scratches and restoration dispersion on film were investigated in aspects of film itself and the interaction of film and incident light. The projected film images were scanned by scanner. The micro-structure and composition of film were analyzed by confocal laser scanning microscope (CLSM) and scanning electronic microscopy (SEM). Optical path of the incident light was analyzed by multi-angle reflectance spectrophotometer, florescence spectrophotometer and ultraviolet spectrophotometer. All these investigations prove that restoration dispersion restores superficial scratches by reducing light scattering and penetrating scratches can not be restored due to the missing of emulsion layer. 


\section{Materials and methods Materials}

The restoration dispersion used in this study was friendly offered by Yuhu Li. It was prepared by mixing water-borne fluorine, nano silica, ethanol, and water-based polyurethane [29]. The black-and-white film was provided by Western Movie Group Co., Ltd. It is a motion picture film with successive frames with a cellulose acetate film base produced in the 1970s. The fluorescence probes 4-(diethylamino)-3-hydroxyflavone (FE) was synthesized as previously described [31].

\section{Projected film image and film surface micro-structure characterization}

One frame of unscratched film and one frame of film with each scratch pattern were selected. The scratched frame was treated half with a thin layer of restoration dispersion by a soft brush. After treatment, the restored films were dried at room temperature. The increase in weight after drying was between 10 and $20 \mathrm{mg}$ with $2-20 \mu \mathrm{m}$ thickness increase for each frame. The projected film images were obtained by scanner (Epson V370).

A high-resolution CLSM (Keyence VK-X250) was employed to obtain surface morphology of the films. The equipment combines a high-resolution optical imaging system and a surface roughness measurement function. The microscope employs a $408 \mathrm{~nm}$ violet laser.

\section{Film composition characterization}

The composition of the unscratched and scratched films was characterized with SEM (FlexSEM 1000) equipped with an energy dispersive X-ray spectrometer (EDS). All samples were coated with Au and the accelerating voltage was set as $20 \mathrm{kV}$ in high vacuum mode.

\section{Optical path characterization}

In order to gain insight into the influence of scratches and the restoration dispersion on the optical path of the light projected on the film, reflectance spectra from different viewing directions were measured by a multiangle spectrophotometer (MA98, X-Rite, USA). The illuminated area is a spot with diameter at $0.4 \mathrm{~cm}$ with specific illumination and measurement angles (Fig. 2). The fraction of the transmitted light was measured by both fluorescence spectrophotometer and ultravioletvisible spectrophotometer by illuminating on a rectangle $1.0 \mathrm{~cm}$ long and $0.4 \mathrm{~cm}$ wide. Fluorescent filter paper was used as a probe and placed under the films, i.e., unscratched, scratched and restored films. The corresponding spectra were recorded by the fluorescence

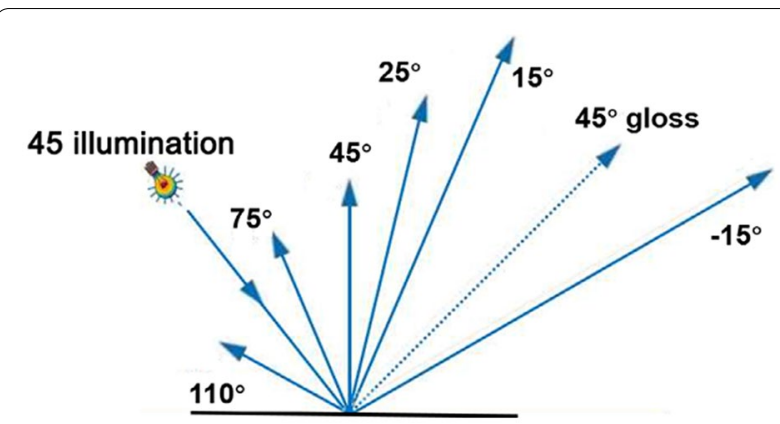

Fig. 2 Sketch of medium illumination and in-plane detection with MA98

spectrophotometer (F-7000, Shimadzu, Japan) with an excitation wavelength of $400 \mathrm{~nm}$. The difference of the fluorescence intensities can reflect the intensity of light transmitted through the films. On the bases of the Beer Lambert Law [32], it is expected that the higher the amount of light absorbed by the sample, the lower is the extent of light transmitted through the sample. The transmitted light was also characterized by ultravioletvisible spectrophotometer (UV WinLabV6) within the wavelength of $450 \mathrm{~nm}-700 \mathrm{~nm}$. For all the above spectra characterization, three measurements were performed on each sample and the error was within 5\% standard deviations.

\section{Results and discussion}

Effect of scratches and restoration dispersion on the projected film image and micro-structure

To be brief, superficial scratches in the film base and emulsion layer are called SF and SE respectively for short. PSE is short for penetrating scratches which completely remove the protective and emulsion layer and further scratch the film base.

Projected images of partially restored film sections with the scratch types, SF, SE, and PSE, show that the scratches disappear in the restored (bottom) part for SF and SE, but are still visible for PSE (Fig. 3, row (A, B, C)). Typical 2D LSCM images of the partially restored films are shown in Fig. 3, row (D). The top-down view of SF and PSE shows the periodic stick slip behavior which is caused by the transition from static to dynamic movement of the scratch tip [33]. The topography of SF shows repeating fish-scale pattern. For PSE, the scratch is a mixture of pseudo fish-scale and material removal and the size of pseudo fish-scale is relatively larger. The similar characteristic of SF and PSE is probably due to that the force moves across the same substrate, film base. For SE, the scratch damage is irregular and denser compared with SF and PSE. As is shown in the 
a

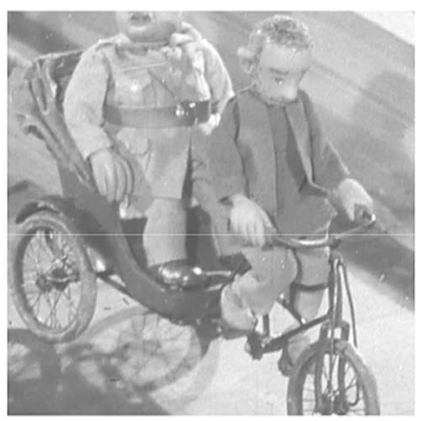

b

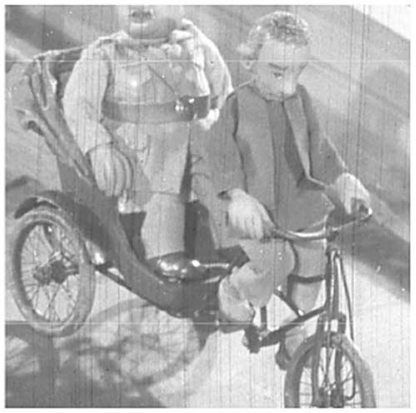

C

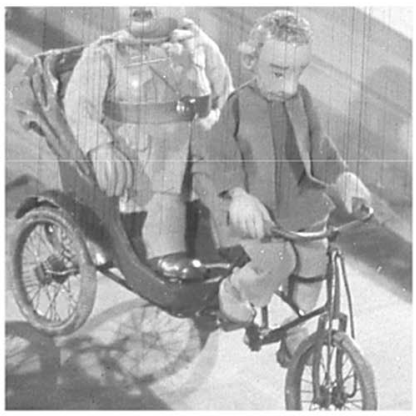

d

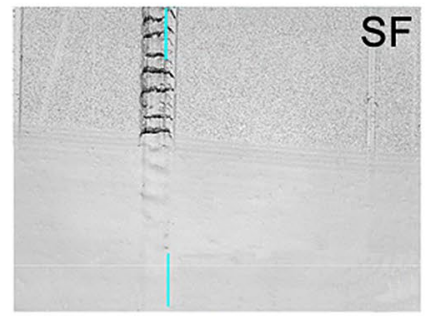

e

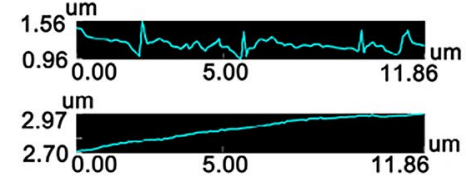

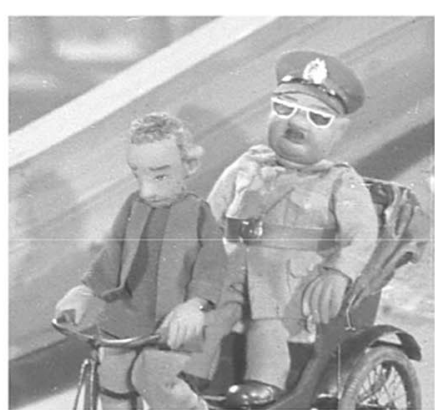
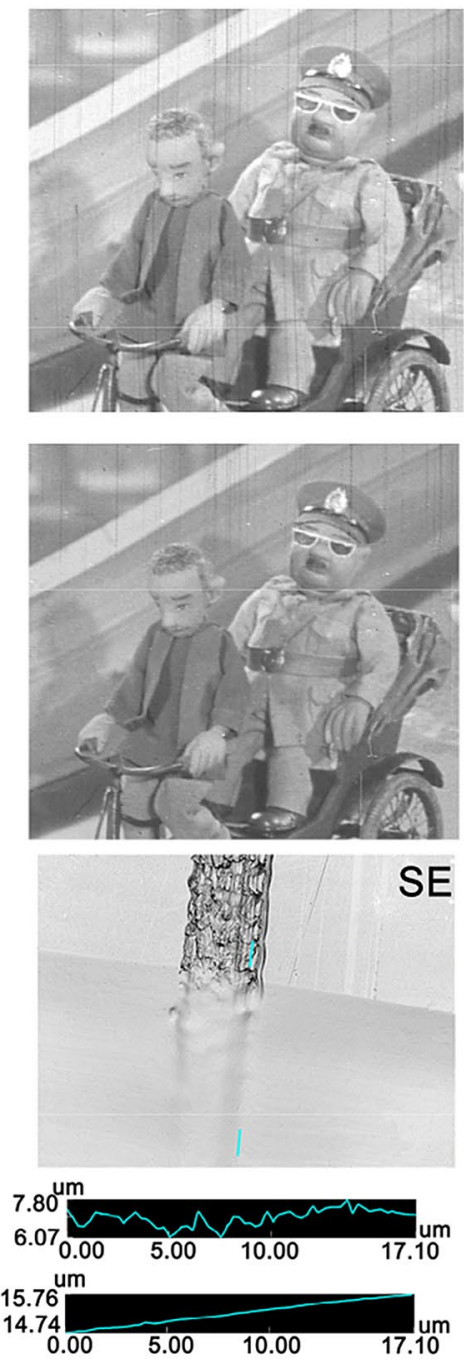
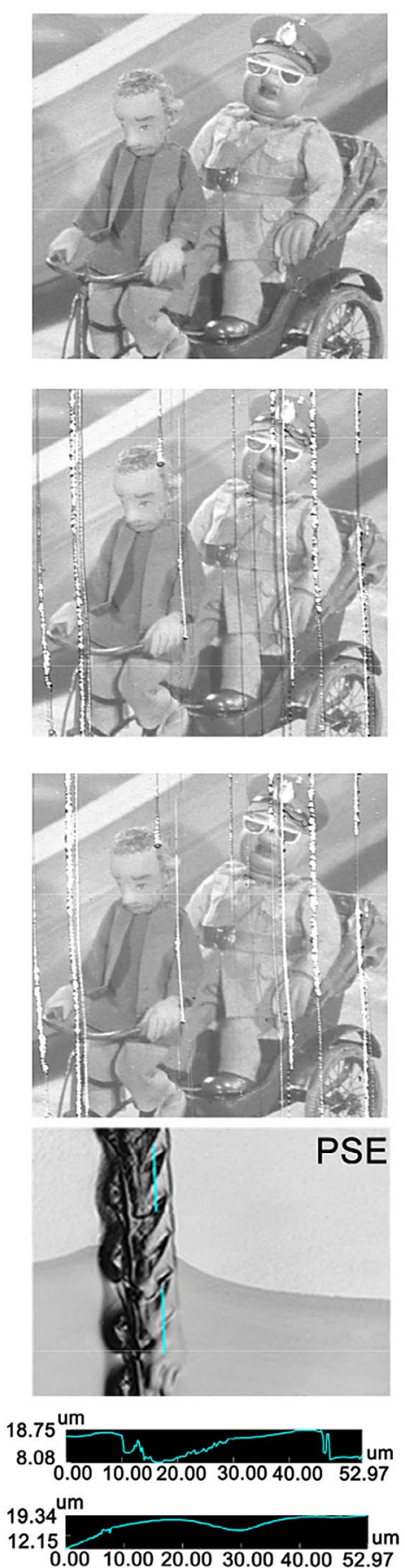

Fig. 3 From top to bottom: Projected film images of (A) unscratched film, (B) scratched film, (C) half restored film; (D) Confocal scanning laser micrographys of scratches with about $5.93 \mu \mathrm{m}$ in width and $65 \mu \mathrm{m}$ in length (SF), $51 \mu \mathrm{m}$ in width and $171 \mu \mathrm{m}$ in length (SE) and $53 \mu \mathrm{m}$ in width and $194 \mu \mathrm{m}$ in length(PSE); (E) Height profile of scratch (first row) and scratch filled with restoration dispersion (second row)

cross-sectional profile of the films (Fig. 3, row (E)), the surface of all the scratched films is rough. After being treated with the restoration dispersion, the restored scratches become relatively smooth. Furthermore, PSE are the deepest and the depths of all the scratched films decrease after being restored. The restoration liquid can completely cover SE and SF while it can only partially cover PSE. 

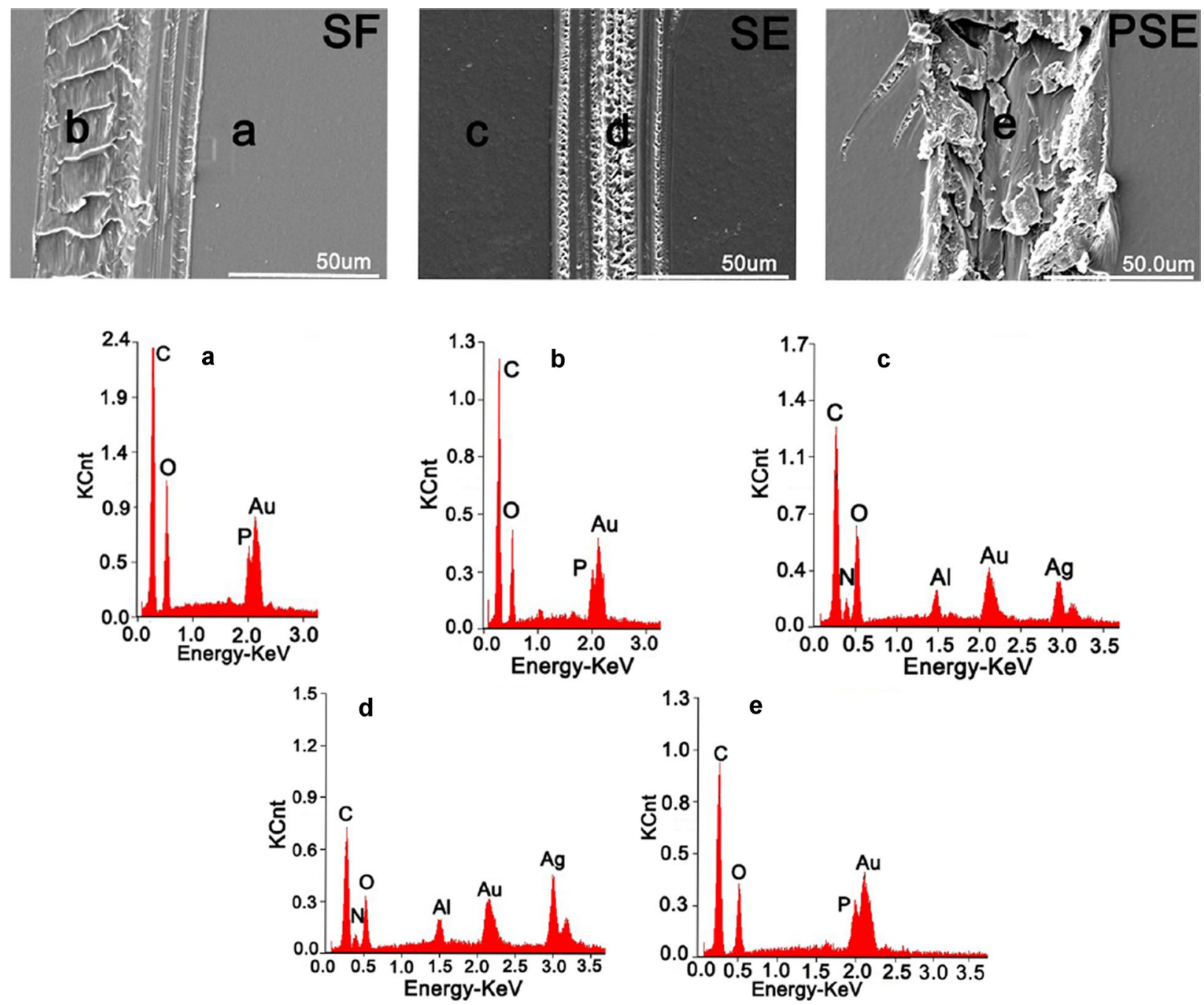

Fig. 4 SEM images of scratch patterns compared to EDS of (a) unscratched film base, (b) scratch $50 \mu \mathrm{m}$ wide and $83 \mu \mathrm{m}$ long on film base, (c) unscratched emulsion layer, (d) superficial scratch $33 \mu \mathrm{m}$ wide and $83 \mu \mathrm{m}$ long on emulsion layer and (e) penetrating scratch $58 \mu \mathrm{m}$ wide and $83 \mu \mathrm{m}$ long on emulsion layer

\section{Effect of scratches on the composition of film}

The EDS spectra show that different scratch patterns reach different layers of the film (Fig. 4). Elements of $\mathrm{C}, \mathrm{N}, \mathrm{P}$, and $\mathrm{Au}$ are found in the unscratched film base (Fig. 4a). After being scratched, the composition of SF does not change (Fig. 4b). In case of SE, before and after being scratched, same elements, i.e., C, N, O, Al, $\mathrm{Ag}$, and $\mathrm{Au}$, are detected (Fig. 4c,d). However, for PSE, element Ag is absent (Fig. 4e) and the elements composition is same with that of SF. These results indicate that SF and SE do not remove the whole layer of film, while PSE causes a loss of the emulsion layer and further damage the film base.

\section{Effect of scratches and restoration dispersion on light reflectance}

A surface with zero roughness would only show specular reflectance. Conversely, for a surface with certain roughness, the light would be reflected in all directions and the intensity of this reflection would depend on the angle between the surface normal and the illuminant $[34,35]$. Therefore, the rough surface of film affects the way the surface reflects light [36-39]. In order to investigate the effect of light scattering caused by the scratches, the multi-angle reflectance spectra of films were shown (Fig. 5). 

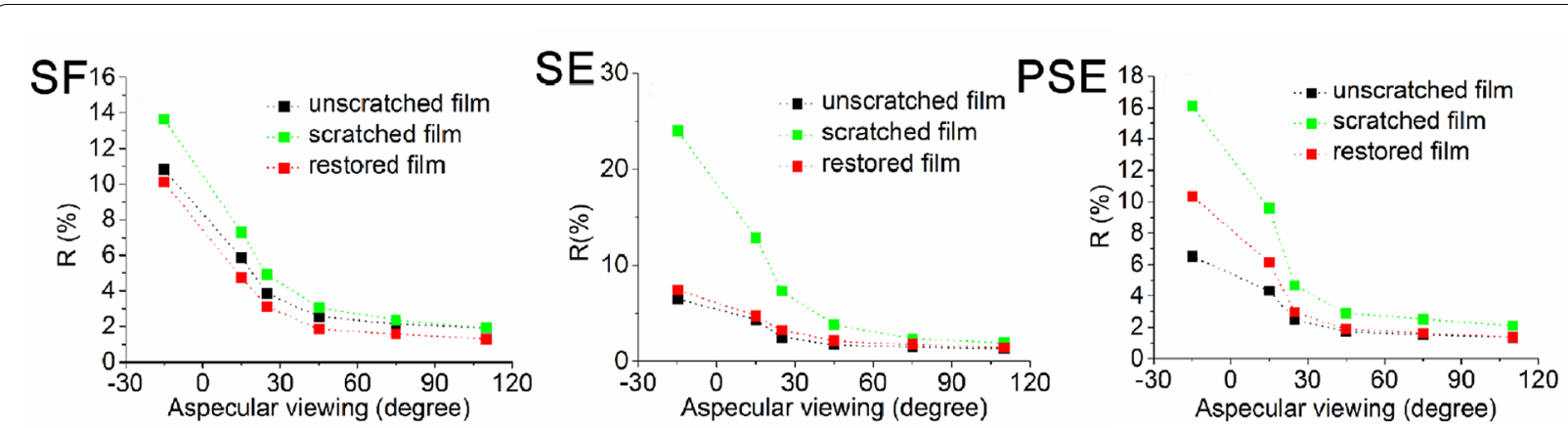

Fig. 5 Multi-angle reflectance spectra of unscratched (black), scratched (green) and restored (red) films

It is worth noticing that, for all three kinds of scratched films, the reflectance spectra intensity of the scratched films is significantly higher than that of the unscratched and restored films particularly in response to specular reflection. Additionally, all the films have the reflection characteristics of a natural rough surface due to the relatively high light intensity distributed in the specular reflection direction [40, 41]. The reflectance spectra intensity of the restored SF is even lower than that of the unscratched film. This is because an unscratched film base is not completely smooth. Even though there are no scratches visible in the projected image of the unscratched film, some minor irregularities and fine scratches still exist. When SF are treated with restoration dispersion, the liquid not only fills the air voids between the visible scratches but also covers those fine scratches that are invisible in the projected image. For SE and PSE, the reflectance spectra intensity of the restored films is slightly higher than that of the unscratched films. It is assumed that SE, featuring a high density of damage, generates intense reflectance spectra in all directions. The restoration dispersion is only able to suppress the scattering effect to some degree. The deep scratches of PSE can only be partially covered by the restoration dispersion. The less evident light reflectance in restored film in comparison with scratched film corresponds well to the reduced roughness of restored film. A similar principle has been reported previously [42].

\section{Effect of scratches and restoration dispersion on light transmission}

Due to the fixed amount of incident light, light scattering can affect light transmission [43, 44]. It is assumed that the scratches change the light transmission or absorption during the film projection. The light transmittance through the film is therefore presented by characterizing fluorescence intensity (Fig. 6). The higher amount of light transmits film, the higher intensity of fluorescent light.

Figure 7 shows the florescence spectra of the unscratched, scratched, and restored films with peaks at about $490 \mathrm{~nm}$ and $560 \mathrm{~nm}$. For SF, the fluorescence intensity of the scratched film base is lower than that of the unscratched film. The fluorescence intensity of the restored film is stronger than that of both the scratched and the unscratched film. As analyzed above, the restoration dispersion also fills the cavities of the scratches, which are invisible in the projected image. Therefore, the fluorescence intensity of the restored film is the strongest. The change of the fluorescence intensity indicates that the intensity of transmitted light through the scratched film is weaker than that through the unscratched film, and the intensity of the transmitted light through the restored film is stronger than that through the scratched and the unscratched film. For SE, the fluorescence intensity of the restored film is stronger than that of the scratched film but lower than that of the unscratched film. This is indicating that the intensity of the light transmittance through the restored film is stronger than that
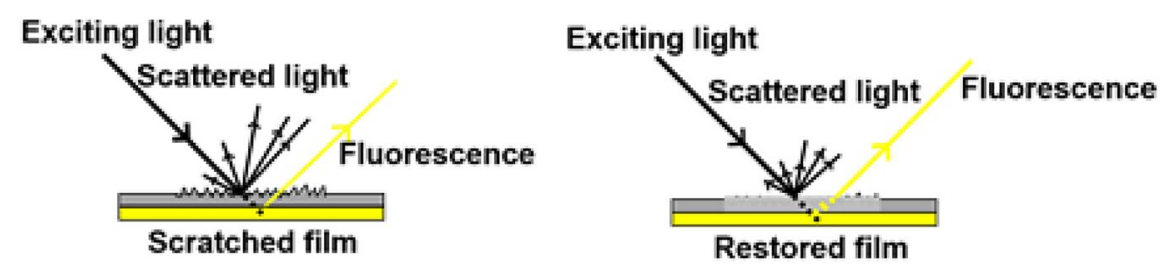

Fig. 6 Schematic diagram for fluorescence to detect the light path of incident light in scratched films without (left) and with (right) filling restoration dispersion 

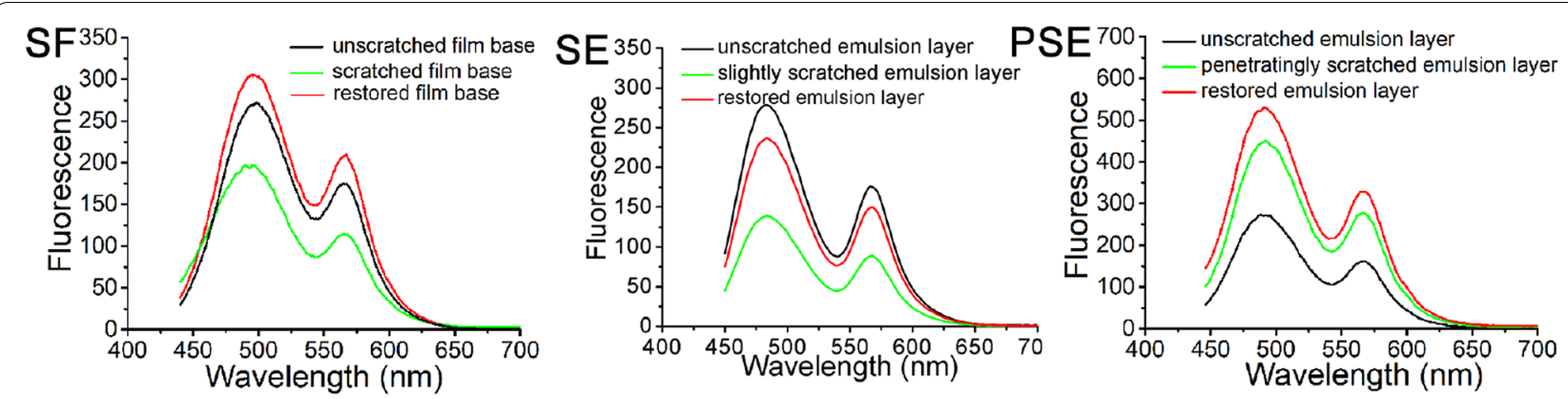

Fig. 7 Fluorescence spectra of unscratched (black), scratched (green) and restored (red) films

through the scratched film, but weaker than that through the unscratched film.

For PSE, the fluorescence intensity of the restored film is stronger than that of the scratched and unscratched films. In addition, the fluorescence intensity of the scratched film is stronger than that of the unscratched film. The change of the light transmittance is identical to the change of the fluorescence intensity. Here, the penetrating scratches remove the black and white emulsion layer and leave a transparent matrix, which can let most of the incident light pass through. Filling scratches with restoration liquid results in a stronger transmitted light due to a lower degree of light scattering induced by partially covered scratches. However, the restored film is not still able to reproduce an image due to the missing emulsion layer.

The transmitted light is confirmed by an ultraviolet spectrophotometer (Fig. 8). As stated in the Beer Lambert Law [32], the intensities of transmitted and absorbed light show opposite trends. For SF and SE, the intensity of the ultraviolet absorption spectrum of the scratched film is higher than that of the unscratched and restored films. For SF, the intensity of the absorbed light of the unscratched film is higher than that of the restored film. For SE, the portion of the absorbed light of the restored film is higher than that of the unscratched film. For PSE, the intensity of the absorbed light of the unscratched film is the highest. The fraction of the absorbed light of the scratched film is higher than that of the restored film. All the results of the ultraviolet absorption spectrum are consistent with the above-mentioned intensities of the transmitted light.

\section{Discussion}

It is demonstrated from the above results that scratches and filling scratches with restoration dispersion have impacts on optical path of incident light and thus the projected film images. As a matter of fact, the optical path of incident light is closely related to the values of refractive indices of different mediums. The refractive indices of the different layers, i.e., protective layer, emulsion layer, film base and antihalation layer of film are 1.6, 1.6, 1.5 and 1.6 respectively [45]. After the pristine film is scratched, scratches increase roughness and introduce air voids with refractive index at 1.00 . The difference in refractive index is between air (1.00) and film (1.5 or 1.6) leading to stronger light scattering. The application of restoration dispersion with refractive index at 1.42 [29] decreases the difference in refractive index from air (1.00) and film (1.52 or 1.6) to restoration dispersion (1.42) and film (1.5 or 1.6) $[46,47]$. Consequently, the smaller difference in refractive indices increases the intensity of transmitted
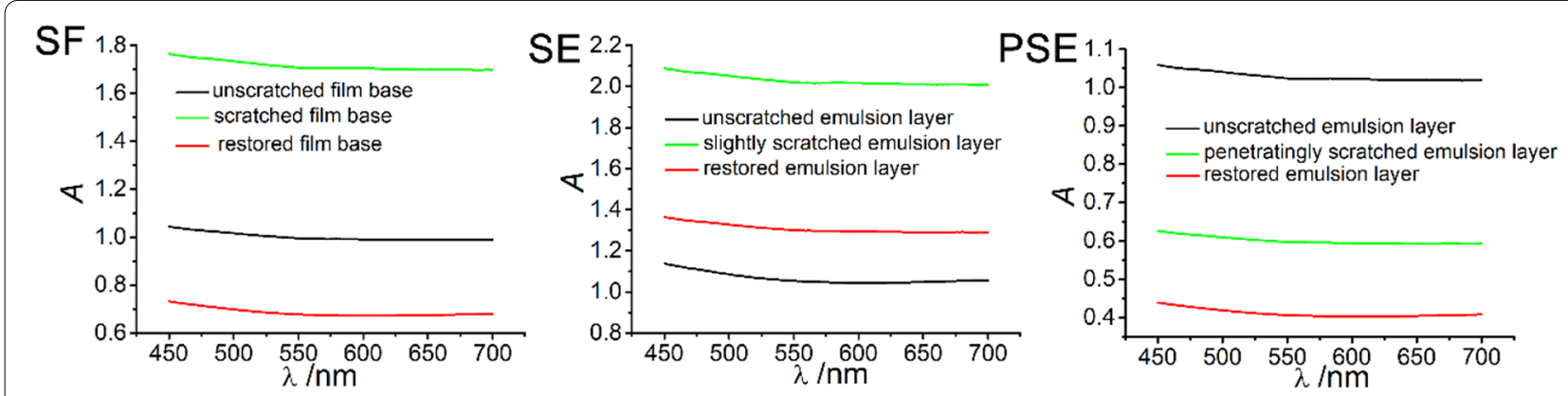

Fig. 8 Ultraviolet-visible absorption spectra of unscratched (black), scratched (green) and restored (red) films 
light resulting the restored projected film images of scratched film base and slightly scratched emulsion layer. In fact, the closer refractive indices of the restoration dispersion and film substrate are, the less visual of scratches are.

\section{Conclusions}

SF and SE are superficial scratches which do not change the composition of film. PSE completely remove emulsion layer. Scratches increase films' roughness while the application of restoration dispersion make the scratches relatively smooth. The roughness of SF and SE leads to higher amount of reflected light and less amount of transmitted light resulting blackness in the projected film image. Filling scratches with restoration dispersion with matching refractive index lowers intensity of light scattering and increases intensity of light transmittance. The images of films with SF and SE therefore reappear in projection. Rough surface of PSE also results stronger intensity of reflected light but higher amount of transmitted light due to the removal of black and white emulsion layer. Filling scratches with the restoration dispersion decreases the roughness and light scattering and increases light transmittance, however the projected film image is still bright due to the loss of the emulsion layer. It can be concluded that the reduce of light scattering by filling restoration material with matching refractive index is a way to decrease the effects of scratch on projected film image when the layered structure is intact. Future perspectives involve making up the removed silver in PSE to restore the film image and exploring effects of scratches on color films.

\begin{abstract}
Abbreviations
SEM: Scanning electron microscopy; EDS: Energy dispersive X-ray spectrometer; CLSM: Confocal laser scanning microscopy; SF: Scratches on the antihalation layer or the film base; SE: Slight scratches on the emulsion layer, which only damage the protective layer but do not reach the emulsion layer; PSE: Penetrating scratches in the emulsion layer, which completely remove the protective layer and the emulsion layer and may scratch the film base.
\end{abstract}

\section{Acknowledgements}

The authors would like to thank Dr. Gesa Schwantes, Xiao Huang and Xiao Ma at the University of Shanghai for their valuable comments and suggestions.

\section{Authors' contributions}

$\mathrm{DH}$ and $\mathrm{HL}$ conceptualized the study; QX and FX carried out the characterization; DH, QX and FX analyzed the data, QX wrote and reviewed the original draft. All authors read and approved the final manuscript.

\section{Funding}

The research was financially supported by the Natural Science Foundation of China (21173140 and 20973105), National Key Research and Development Project of China (No. 2019YFC1520104, 2019YFC1520504) and Key Program of National Natural Science Foundation of China (No.51732008).

\section{Data availability}

The datasets used and/or analysed during the current study are available from the corresponding author on reasonable request.

\section{Declarations}

Competing interests

The authors declare no competing interests.

\section{Author details}

${ }^{1}$ School of Materials Science and Engineering, Shanghai University, Shanghai, China. ${ }^{2}$ Institute for the Conservation of Cultural Heritage, Shanghai University, Shanghai, China. ${ }^{3}$ Engineering Research Center of Historical and Cultural Heritage Protection, Ministry of Education, School of Materials Science and Engineering, Shaanxi Normal University, Xi'an, China.

Received: 30 April 2021 Accepted: 17 June 2021

Published online: 05 July 2021

\section{References}

1. Sahyun M. Mechanisms photographic chemistry. J Chem Educ. 1974;51(2):72-7.

2. Sheppard SE. The chemistry of photography. I. Historical considerations. J Chem Educ. 1927;4(3):298.

3. Trumpy G. Photographic film and its interaction with light: detection of dust and scratches for image restoration; 2013.

4. Sattar S. The chemistry of photography: still a terrific laboratory course for nonscience majors. J Chem Educ. 2017;94(2):183-9.

5. Sahyun MRV, Serpone N. Mechanisms of latent image formation in photothermographic silver imaging media. J Imaging Sci Technol. 1996;40(2):94-103.

6. Briscoe BJ, Sinha SK. Scratch resistance and localised damage characteristics of polymer surfaces - a review. Mat Wiss u Werkstofftech. 2003;34(10-11):989-1002.

7. Jiang $\mathrm{H}$, Browning $\mathrm{R}$, Sue $\mathrm{H}$. Understanding of scratch-induced damage mechanisms in polymers. Polymer (Guildf). 2009;50(16):4056-65.

8. Friedrich K, Sue HJ, Liu P, Almajid AA. Scratch resistance of high performance polymers. Tribiol Int. 2011;44(9):1032-46.

9. Motamedi P, Bagheri R. Study of the scratch resistance criteria and their relationship with mechanical properties and microstructure in a ternary thermoplastic blend. Wear. 2017;386-387:118-28.

10. Jiang $H$, Cheng $Q$, Jiang C, Zhang J, Li Y. Tribology international effect of stick-slip on the scratch performance of polypropylene. Tribol Int. 2015;91:1-5.

11. Wittmann B, Gauthier C, Burr A, Agassant J, Favier D, Montmitonnet P, Casoli A. Study of scratch resistance of a hard-on-soft polymer bilayer: combination of in situ vision, X-ray tomography and numerical simulations. Wear. 2020;452:452-3.

12. Wong M, Lim GT, Moyse A, Reddy JN, Sue H-J. A new test methodology for evaluating scratch resistance of polymers. Wear. 2004;256:1214-27.

13. Bull SJ. Failure mode maps in the thin film scratch adhesion test. Tribol Int. 1997:30(7):491-8.

14. Ni BY, Le Faou A. Scratching behaviour of polymer films using blunt spherical styli. J Mater Chem. 1996;31(15):3955-63.

15. Burnett PJ, Rickerby DS. The relationship between hardness and scratch adhesion. Thin Solid Film. 1987;154(1-2):403-16.

16. Demirci I, Gauthier C, Schirrer R. Mechanical analysis of the damage of a thin polymeric coating during scratching: role of the ratio of the coating thickness to the roughness of a scratching tip. Thin Solid Films. 2005;479:207-15.

17. Hara Y, Mori T, Fujitani T. Relationship between viscoelasticity and scratch morphology of coating films. Prog Org Coat. 2000;40:39-47.

18. Calhoun JM, DA Leister. Effect of gelatin layers on the dimensional stability of photographic film. Photogr Sci Eng. 1959;3.

19. Jiang $H$, Browning $R L$, Hossain MM, Sue H, Fujiwara M. Quantitative evaluation of scratch visibility resistance of polymers. Appl Surf Sci. 2010;256:6324-9.

20. Gamonal-Repiso P, Sanchez-Soto M, Santos-Pinto S, Maspoch ML. Influence of topography on the scratch and mar visibility resistance of randomly micro-textured surfaces. Wear. 2019. https://doi.org/10.1016/j. wear.2019.203082. 
21. Hamdi M, Sue H. Effect of color, gloss, and surface texture perception on scratch and mar visibility in polymers. Mater Des. 2015;83:528-35.

22. Rangarajan P, Sinha M, Watkins V, Harding K, Sparks J. Scratch visibility of polymers measured using optical imaging. Polym Eng Sci. 2003:43(3):749-58.

23. Fletcher TE. A simple model to describe relationships between gloss behaviour, matting agent concentration and the rheology of matted paints and coatings. Prog Org Coat. 2002;44:25-36.

24. Arin I, Kleist U, Mattsson L, Rigdahl M. On the relation between surface texture and gloss of injection-molded pigmented plastics. Polym Eng Sci. 2005;45(10):1343-56.

25. Wittmann B, Montmitonnet P, Burr A, Gauthier C, Agassant J, Casoli A. BRDF and gloss computation of polyurethane coatings from roughness measurements: modelling and experimental validation. Prog Org Coat. 2021;156.

26. Maskery SE. Development and applications for matting agents. Pigment Resin Technol. 1973;2:11-9.

27. Yonehara M, Matsui T, Kihara K, Isono H, Kijima A, Sugibayashi T. Experimental relationships between surface roughness, glossiness and color of chromatic colored metals. Mater Trans. 2004;45(4):1027-32.

28. Apostol BF. Scattering of the electromagnetic waves from a rough surface. J Mod Opt. 2012;59(18):1607-16.

29. Yuhu L, Dengcui M, Yajun Z. Restoration dispersion for scaratched cinefilm; 2010.

30. Yajun Z, Yuhu L, Dengcui M, Juanli W, Yanhong Z, Shan L. Restoration research on scratched cine-film. Arch Sci Study. 2010;6:55-8.

31. Ozturk T, Klymchenko AS, Capan A, Oncul S, Cikrikci S, Taskiran S, Tasan B, Kaynak FB, Demchenko AP. New 3-hydroxyflavone derivatives for probing hydrophobic sites in microheterogeneous systems. Tetrahedron. 2007;63:10290-9.

32. Commoner B, Lipkin D. The application of the Beer-Lambert law to optically anisotropic systems. Science (80-). 1949;110:41-3.

33. Baum MJ, Heepe L, Gorb SN. Friction behavior of a microstructured polymer surface inspired by snake skin. Beilstein J Nanotechnol. 2014;5:83-97.

34. López AJ, Pozo-antonio JS, Ramil A, Rivas T. Influence of the commercial finishes of ornamental granites on roughness, colour and reflectance. Constr Build Mater J. 2018;182:530-40.

35. Lee RJ, Smithson HE. Low levels of specularity support operational color constancy, particularly when surface and illumination geometry can be inferred. J Opt Soc Am A Res. 2016:33(3):A306-18.
36. Elif G, Alper M, Haclismailoglu M. Optical design of light guide prisms with surface roughness for automotive tail lights. J Automob Eng. 2020;234(9):2393-401.

37. Niu C, Zhu T, Lv Y. Influence of surface morphology on absorptivity of light-absorbing materials. Int J Photoenergy. 2019;2019:1-9.

38. Park Y. Surface roughness effects on light propagation in optical light pipes; 2016.

39. Cuppo FLS, García-Valenzuela A, Olivares JA. Influence of surface roughness on the diffuse to near-normal viewing reflectance factor of coatings and its consequences on color measurements. Color Res Appl. 2013;38(3):177-87.

40. Oren M, Nayar SK. Generalization of the Lambertian model and implications for machine vision. Int J Comput Vis. 1995;14:227-51.

41. Zheng LZ, Liang XT, Li SR, Li YH, Hu DD. Fading and showing mechanisms of ancient color relics based on light scattering induced by particles. RSC Adv. 2018:8:1124-31.

42. Jh W, Db F, Julie B-G, Castaneda IS, Nowaczyk N. Sediment colour reflectance spectroscopy as a proxy for wet/dry cycles at Lake El'gygytgyn, Far East Russia, during marine isotope stages 8 to 12. Sedimentology. 2014:61:1793-811.

43. Whitmore PM, Bogaard J. Determination of the cellulose scission route in the hydrolytic and oxidative degradation of paper. Restaurator. 1994;15(1):26-45

44. Pfaender J, Gray SM, Rick IP, Chapuis S, Hadiaty RK, Herder F. Spectral data reveal unexpected cryptic colour polymorphism in female sailfin silverside fish from ancient Lake Matano. Hydrobiol. 2014;739:155-61.

45. Polyanskiy M. Refractive index database. http://refractiveindex.info. 2013.

46. Fabritius T, Myllyl R. Investigation of swelling behaviour in strongly scattering porous media using optical coherence tomography. J Phys D Appl Phys. 2006;39:2609-12.

47. Juuti M, Koivunen K, Silvennoinen M, Paulapuro H, Peiponen K. Light scattering study from nanoparticle-coated pigments of paper. Colloids Surf A Physicochem Eng Asp. 2009;352:94-8.

\section{Publisher's Note}

Springer Nature remains neutral with regard to jurisdictional claims in published maps and institutional affiliations.

\section{Submit your manuscript to a SpringerOpen ${ }^{\circ}$ journal and benefit from:}

- Convenient online submission

- Rigorous peer review

- Open access: articles freely available online

- High visibility within the field

- Retaining the copyright to your article

Submit your next manuscript at springeropen.com 